
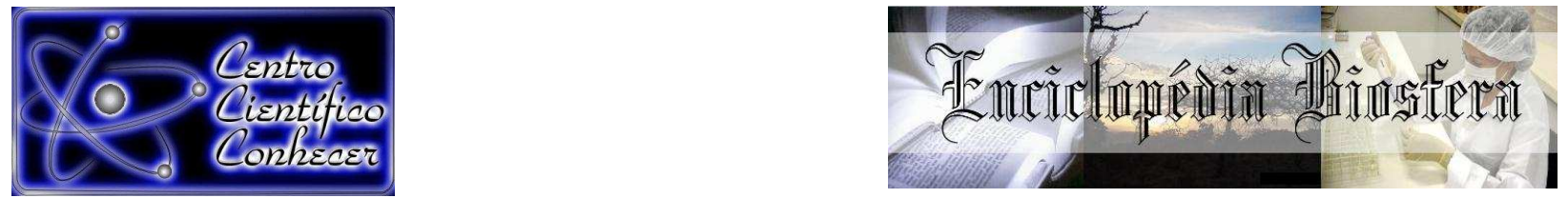

\title{
ESCARIFICAÇÃO MECÂNICA EM CILINDRO ROTATIVO É VIÁVEL PARA A SUPERAÇÃO DA DORMÊNCIA DE SEMENTES DE PAU-FERRO
}

\author{
Evandro Luiz Missio ${ }^{1}$, Cleber Witt Saldanha ${ }^{2}$, Joseila Maldaner ${ }^{3}$, Rosana Matos de \\ Morais $^{4}$, Gerusa Steffen ${ }^{5}$
}

1- Pesquisador Doutor da Fundação Estadual de Pesquisa Agropecuária, Centro de Pesquisa em Florestas, Santa Maria, RS, Brasil evandro@fepagro.rs.gov.br.

2- Pesquisador Doutor da Fundação Estadual de Pesquisa Agropecuária, Centro de Pesquisa em Florestas, Santa Maria, RS, Brasil.

3- Pesquisadora Doutora da Fundação Estadual de Pesquisa Agropecuária, Centro de Pesquisa em Florestas, Santa Maria, RS, Brasil.

4- Pesquisadora Doutora da Fundação Estadual de Pesquisa Agropecuária, Centro de Pesquisa em Florestas, Santa Maria, RS, Brasil.

5- Pesquisadora Doutora da Fundação Estadual de Pesquisa Agropecuária, Centro de Pesquisa em Florestas, Santa Maria, RS, Brasil.

Recebido em: 03/10/2016 - Aprovado em: 21/11/2016 - Publicado em: 05/12/2016 DOI: 10.18677/EnciBio_2016B_043

\begin{abstract}
RESUMO
Caesalpinia ferrea é uma espécie arbórea nativa que possui importância em programas de restauração florestal. Multiplica-se por sementes, as quais apresentam dormência tegumentar, dificultando a propagação em viveiro. Diante do exposto, objetivou-se verificar a eficiência da escarificação mecânica em cilindro rotativo para a superação de dormência de sementes de pau-ferro. O delineamento experimental empregado foi 0 inteiramente ao acaso sendo avaliados seis tempos de escarificação com lixa em cilindro rotativo $(0,5,10,15,20$ e 25 segundos), com quatro repetições. Foi avaliado o índice de velocidade de germinação, primeira contagem de germinação, porcentagens de germinação e de sementes mortas acumuladas. Verificou-se que a escarificação mecânica com lixa em cilindro rotativo é uma técnica eficaz para a superação da dormência de sementes de pau-ferro, sendo que o tempo de 15 segundos é o recomendado para a obtenção de germinação mais rápida e com maiores percentuais acumulados. A escarificação mecânica com lixa em cilindro rotativo é uma prática recomendada para a propagação de pau-ferro em viveiro de produção de mudas.
\end{abstract}

PALAVRAS-CHAVE: Caesalpinia ferrea, produção de mudas, sementes florestais.

\section{MECHANICAL SCARIFICATION WITH DRUM ROTATING IS VIABLE FOR OVERCOMING DORMANCY ON PAU-FERRO SEEDS}

\begin{abstract}
Caesalpinia ferrea is a native tree species that has importance in forest restoration programs. Multiplied by seeds, which have cutaneous numbness, hindering the spread in nursery. Given the above, aimed to check the mechanical scarification ENCICLOPÉDIA BIOSFERA, Centro Científico Conhecer - Goiânia, v.13 n.24; p.476 2016
\end{abstract}


efficiency rotating cylinder to overcome dormancy pau-ferro seeds. The experimental design was completely randomized and evaluated six times scarification with sandpaper rotating cylinder $(0,5,10,15,20$ and 25 seconds), with four replications. the germination speed index, first count, germination percentage and accumulated dead seeds was evaluated. It was found that the mechanical scarification with sandpaper rotating cylinder is an effective technique for overcoming dormancy pauferro seeds, with the time of 15 seconds is recommended to obtain faster and with greater cumulative percentage germination. Mechanical scarification with sandpaper in rotating cylinder is a best practice for the spread of pau-ferro in seedling production nursery.

KEYWORDS: Caesalpinia ferrea, seedling production, forest seeds.

\section{INTRODUÇÃO}

A exploração desordenada da mata atlântica faz com que ocorra a necessidade de reparação aos danos causados ao meio ambiente. Neste contexto, programas de restauração florestal têm demandado grandes quantidades de mudas para atender aos diferentes cenários que envolvem esta problemática (RODRIGUES \& BRANCALION, 2010).

Neste sentido, a pesquisa na área de tecnologia de sementes de espécies florestais nativas possui grande importância, pelo fato de fornecer informações que subsidiem a propagação de mudas de qualidade visando à utilização em programas de restauração florestal (BASKIN \& BASKIN, 2014).

Uma espécie de ocorrência natural em vários estados brasileiros e que possui importância para programas de recuperação de áreas degradadas, recomposição de áreas desmatadas e de preservação permanente é Caesalpinia ferrea Mart. ex Tul. (Fabaceae), também conhecida como pau-ferro (LORENZI, 2000; CARVALHO, 2003). Sua multiplicação ocorre por sementes, as quais apresentam germinação baixa e lenta e com baixos percentuais, refletindo em baixa porcentagem de emergência em viveiro.

Este problema ocorre devido à impermeabilidade do tegumento, o qual ocasiona um tipo de dormência caracterizada como tegumentar ou exógena (CARVALHO, 2003; FERREIRA \& BORGHETTI, 2004; OLIVEIRA, 2012). Esta forma de dormência é comum em sementes de algumas espécies florestais, em especial da família Fabaceae, devido à presença de camada cerosa, deposição de lignina e de ácidos graxos nas camadas de células paliçádicas (MARCOS FILHO, 2005). Como alternativa, existem técnicas que visam remover esta barreira física para que se obtenham ganhos significativos nos percentuais de germinação, além da diminuição do tempo entre a semeadura e emergência da plântula.

A literatura destaca resultados obtidos com diferentes metodologias para a superação da dormência em sementes de $C$. ferrea, especialmente trabalhos envolvendo o uso de ácido sulfúrico e lixa manual (BIRUEL et al., 2007; COELHO et al., 2010; AVELINO et al., 2012; COELHO et al., 2013). Tais técnicas são eficazes para a superação da dormência tegumentar da semente, porém, de difícil aplicabilidade prática em viveiro, especialmente quando se trata da escarificação ácida. Cabe destacar que a escarificação com lixa é uma alternativa que possui boa aplicabilidade em viveiro, contudo, necessita de adaptações para que possa se 
tornar eficiente e funcional para o viveirista, principalmente quando o objetivo é produzir grande número de mudas.

Estudos envolvendo o uso de lixa para a superação da dormência de sementes em outras espécies florestais mostraram resultados satisfatórios. Para Hymenaea courbaril L., estudos mostraram que a escarificação mecânica manual é adequada para a superação da dormência das sementes (FREITAS et al., 2013; GOMES et al., 2013). O mesmo foi observado para Erythrina velutina Willd. (SANTOS et al., 2013), Schizolobium parahyba (Vell), Enterolobium contorstisiliquum (Vell.) Morong (ANDREANI JÚNIOR et al., 2014), Parkinsonia aculeata L. (AGRA et al., 2015) e Albizia pedicellaris (DC.) L. (FREIRE et al., 2016).

Diante do exposto, objetivou-se verificar a eficiência da escarificação mecânica em cilindro rotativo para a superação da dormência de sementes de pauferro.

\section{MATERIAL E MÉTODOS}

Foram utilizadas sementes da espécie $C$. ferrea (pau-ferro), pertencentes ao lote n43 de 2013, com pureza de 99\%, umidade de $11,6 \%$ e massa de mil sementes de 119,92 gramas. A coleta foi efetuada de cinco árvores matrizes $\left(30^{\circ} 09^{\prime}\right.$ $43^{\prime \prime} 53^{\circ} 35^{\prime}$ 07"O) localizadas no Município de Sã o Sepé, Rio Grande do Sul. Após a coleta e beneficiamento, o lote de sementes foi armazenado em câmara fria-seca com temperatura (6 a $\left.9{ }^{\circ} \mathrm{C}\right)$ e umidade relativa do ar (30 a 60\%) controladas até a montagem do experimento.

O experimento foi conduzido em delineamento inteiramente casualizado, com seis tempos de escarificação com lixa (0, 5, 10, 15, 20 e 25 segundos), todos com quatro repetições para cada tratamento. Para aplicação dos tratamentos foi utilizada uma lixa ( $\mathrm{n}^{-}$80), dimensionada para um escarificador do tipo cilindro elétrico $\left(\mathrm{WEG}^{\circledR}\right)$, com diâmetro de $20 \mathrm{~cm}$ e dotado de quatro hastes giratórias, com rotação de 1725 rpm. Cada tratamento contou com 200 sementes, as quais foram subdivididas em quatro repetições de 50 sementes, conforme metodologia descrita por BRASIL (2013).

Cada repetição foi alocada no interior do cilindro, e posteriormente, cronometrado os tempos de escarificação em lixa. Após a aplicação dos tratamentos, as sementes foram imersas em hipoclorito de sódio na concentração de $5 \%(\mathrm{v} / \mathrm{v})$, lavadas e distribuídas em papel substrato do tipo Germitest ${ }^{\circledR}$, e forma a conter 50 sementes para cada repetição. O papel foi umidecido com água destilada na proporção de duas vezes a sua massa e após a colocação das sementes foi levado para um germinador do tipo Mangelsdorf com temperatura de $25 \pm 1^{\circ} \mathrm{C}$, onde permaneceu até o final das avaliações (BRASIL, 2013).

Foram avaliadas as seguintes variáveis: Germinação acumulada Realizado com quatro subamostras de 50 sementes, sendo as contagens realizadas aos sete e 14 dias, conforme descrito por BRASIL (2013). O resultado da avaliação foi expresso em porcentagem; Mortas acumulada - Realizada concomitantemente com a germinação acumulada, sendo que as sementes que não germinaram ou continuavam firmes foram consideradas mortas (BRASIL, 2013). O resultado da avaliação foi expresso em porcentagem; Índice de velocidade de germinação (IVG) - Para determinação do IVG efetuaram-se contagens diárias da germinação, até totalizar sete dias, sendo consideradas germinadas as sementes que 
apresentavam $2 \mathrm{~mm}$ ou mais de protrusão da radícula. Os valores obtidos foram calculados pela seguinte fórmula: IVG $=\mathrm{G} 1 / \mathrm{N} 1+\mathrm{G} 2 / \mathrm{N} 2+\ldots \mathrm{Gn} / \mathrm{Nn}$, onde: IVG = índice de velocidade de germinação; $\mathrm{G} 1, \mathrm{G} 2, \ldots \mathrm{Gn}$ = número de plântulas normais computadas na primeira contagem, na segunda contagem e na última contagem; N1, $\mathrm{N} 2, \ldots \mathrm{Nn}$ = número de dias da semeadura à primeira, segunda e última contagem (MAGUIRE, 1962); Primeira contagem de germinação - Realizada simultaneamente com a primeira avaliação de germinação acumulada. Neste teste, as plântulas consideradas normais que germinaram foram contadas e retiradas, partindo do princípio de que são mais vigorosas por germinarem mais rapidamente. O resultado da avaliação foi expresso em porcentagem; Condutividade elétrica Conduzido seguindo as recomendações de KRZYZANOWSKI et al. (1999), em que cada tratamento foi subdividido em quatro repetições de 50 sementes, com massas conhecidas, em recipientes com capacidade de $100 \mathrm{~mL}$, adicionando-se $75 \mathrm{~mL}$ de água destilada. Os recipientes foram mantidos em germinador com temperatura ajustada para $25 \pm 1 \stackrel{\circ}{C}$ por 24 horas. Após o período, procedeu-se a leitura em condutivímetro $\left(\right.$ Tecnal $\left.^{\circledR}\right)$. O resultado foi obtido por meio da divisão da leitura pela massa das sementes, sendo expresso em $\mu \mathrm{cm}^{-1} \mathrm{~g}^{-1}$. variância.

Após as avaliações, os dados foram submetidos à regressão na análise da

\section{RESULTADOS E DISCUSSÃO}

Todas as variáveis responderam aos diferentes tempos de escarificação com lixa no 80 em cilindro rotativo (Figuras 1 e 2).O maior índice de velocidade de germinação (IVG) das sementes de $C$. ferrea foi obtido no tempo de 15 segundos de escarificação com lixa $(9,2)$, sendo que o ponto de máxima eficiência técnica (PMET) foi observado em 14,8 segundos (Figura 1a).

Este resultado mostra que as sementes germinaram mais rapidamente quando comparadas aos demais tratamentos, sendo que o índice foi 7,3 vezes superior à testemunha $(2,47)$, sem escarificação. Em sementes de Bumelia obtusifolia Roem. \& Schult. (Sapotaceae), NASCIMENTO (2013) também obteve o maior IVG com o uso da escarificação mecânica com lixa. Comportamento semelhante também foi obtido para Bixa orellana L. (Bixaceae), onde a escarificação com lixa resultou em elevado IVG, o que permitiu melhor a expressão do vigor das sementes (PICOLOTTO et al., 2013).

A primeira contagem de germinação $(73,8 \%)$ apresentou maiores percentuais no tempo de 15 segundos de escarificação com lixa em cilindro rotativo, sendo o ponto máxima de eficiência técnica (PMET) obtido no tempo de 13,5 segundos. A testemunha obteve apenas $28,8 \%$ de sementes germinadas, 45,05 pontos percentuais a menos que o tempo de 15 segundos (Figura 1b). Este resultado de vigor mostra a eficiência do método em promover a germinação mais rápida e com elevados percentuais, possibilitando maiores chances de sucesso na emergência das plântulas. Estudando metodologias para a superação da dormência em sementes de $B$. orellana, PICOLOTTO et al. (2013) também constataram que a escarificação com lixa foi uma das técnicas que contribuiu para os maiores percentuais de germinação acumulada. 

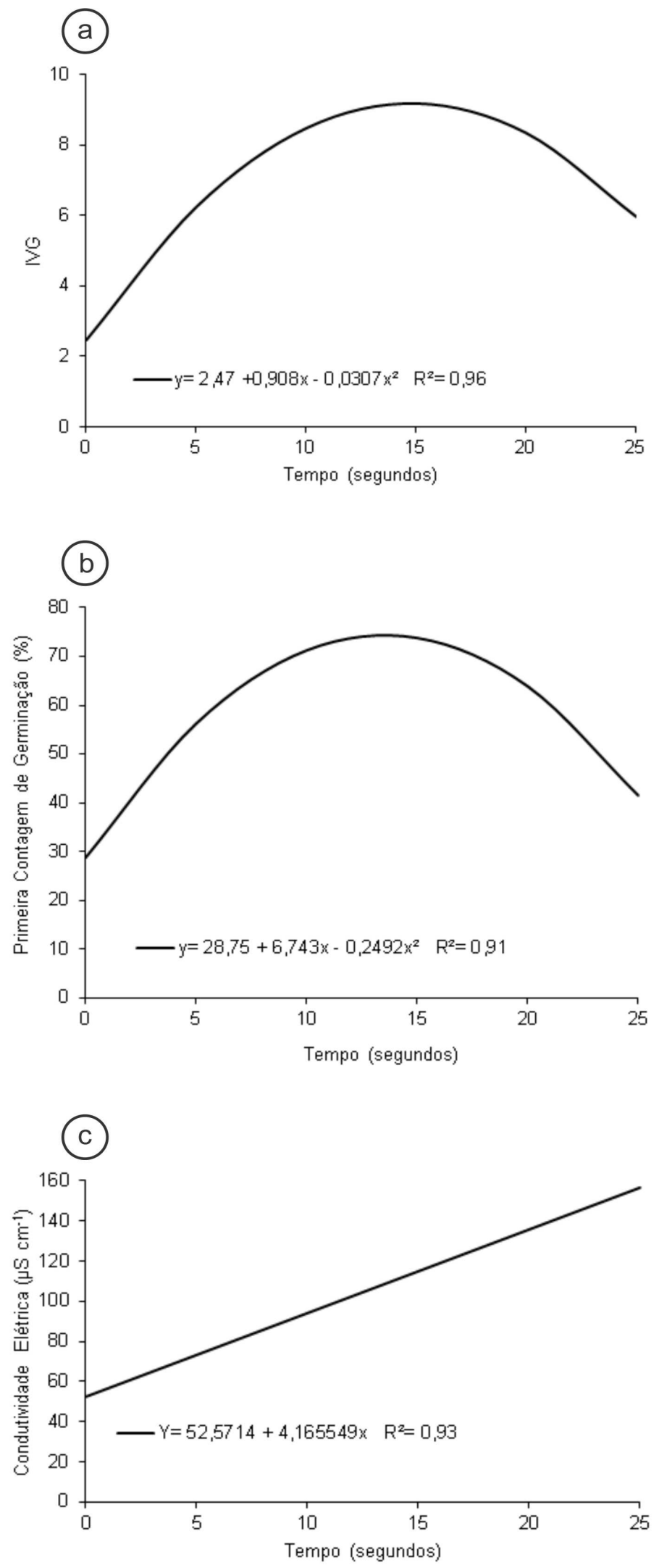

FIGURA 1 - Índice de velocidade de germinação (a), primeira contagem de germinação (b) e condutividade elétrica (c) em sementes de $C$. ferrea submetidas a diferentes tempos de escarificação mecânica com lixa em cilindro rotativo. Santa Maria-RS, 2016. 
O conhecimento do potencial fisiológico das sementes permite a produção de mudas com tamanho e qualidade uniformes, com vantagens no desenvolvimento das plantas (KIKUTI \& MARCOS FILHO, 2012). No caso de C. ferrea, os resultados de vigor obtidos servem para reforçar a eficiência da escarificação mecânica como alternativa para a superação da dormência das sementes com eficiência e rapidez. Tendo em vista, que a superação de dormência é uma das exigências para que se obtenham mudas de qualidade, garantindo que a semente possa expressar o potencial fisiológico durante o processo de germinação.

Com relação à condutividade elétrica (Figura 1c), a concentração de eletrólitos na solução exibiu relação direta e linear com o aumento dos tempos de escarificação das sementes com lixa em cilindro rotativo. O aumento do tempo de exposição das sementes de $C$. ferrea à abrasividade da lixa, resultou no desgaste crescente do tegumento, provavelmente pelo contato da lixa com as estruturas de reserva da semente, principalmente nos dois maiores tempos de escarificação (20 e 25 segundos).

Nestes tempos, houve a diminuição do vigor das sementes, provavelmente por danos causados ao embrião, refletindo na redução do IVG, primeira contagem de germinação e germinação acumulada (Figuras 1a, 1b e 2a), além de elevar o percentual de sementes mortas (Figura 2b). No tempo de 15 segundos de escarificação, apesar de ocorrer aumento na concentração de eletrólitos quando comparado aos menores tempos, aparentemente não houve danos ao embrião das sementes, fato comprovado pelos melhores resultados de vigor e germinação. Adicionalmente, os resultados obtidos para o percentual de sementes mortas acumulado mostram que os maiores danos ocorreram nos tempos de 20 e 25 segundos, tratamentos estes que apresentaram maior extravasamento de eletrólitos.

A germinação acumulada mostrou o mesmo modelo de equação do IVG e primeira contagem de germinação. A maior germinação acumulada $(74,2 \%)$ foi obtida no tempo de 15 segundos de escarificação com lixa em cilindro rotativo, com PMET em 12,8 segundos (Figura 2a). Os valores obtidos são considerados satisfatórios para a espécie em estudo visando à propagação em larga escala. Esta afirmação baseia-se na comparação com trabalhos envolvendo o uso da escarificação ácida, a qual é bastante agressiva ao tegumento, e que proporcionou para a mesma espécie, germinação de no máximo $79 \%$ em imersão por 60 minutos (BIRUEL et al., 2007) e 64\% em imersão por 20 minutos (MEDEIROS et al., 2013).

Em sementes de $E$. contortisiliquum a escarificação manual com lixa foi a técnica que resultou nos maiores percentuais de germinação das sementes, sendo recomenda para a superação da dormência da espécie (FERREIRA et al., 2013). Resultados satisfatórios com o uso de lixa também foram obtidos para B. obtusifolia, onde a escarificação rendeu percentuais de germinação de $98 \%$, sendo esta considerada a técnica mais adequada para a superação da dormência tegumentar da espécie (NASCIMENTO, 2013).

O percentual final de sementes mortas acumulado mostrou um comportamento quadrático negativo, oposto ao da germinação, sendo que a partir do tempo de 20 segundos este percentual apresentou valores elevados, fato que provavelmente esteja associado ao dano mecânico em função do aumento do tempo de exposição das sementes à lixa (Figura 2b). Este resultado é reforçado pela maior condutividade elétrica obtida nos tempos de 20 e 25 segundos, o que mostra a 
associação entre o elevado extravasamento de eletrólitos e o alto percentual de sementes mortas.
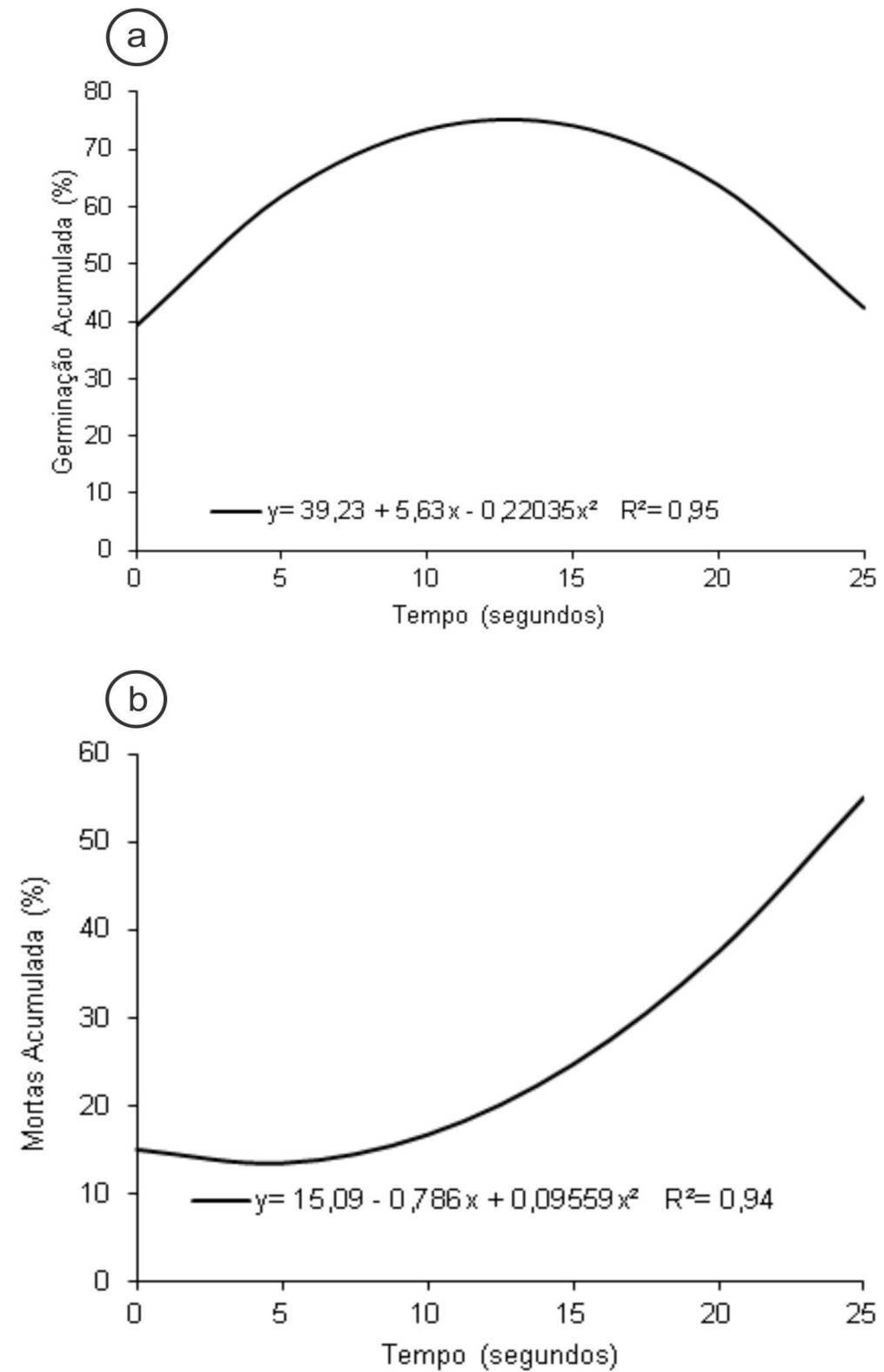

FIGURA 2 - Germinação acumulada (a) e mortas acumulada (b) em sementes de $C$. ferrea submetidas a diferentes tempos de escarificação mecânica com lixa em cilindro rotativo. Santa Maria-RS, 2016.

Os resultados de germinação obtidos neste trabalho mostram a eficiência da associação entre lixa e cilindro rotativo na superação da dormência tegumentar das sementes de $C$. ferrea. Por meio destas informações, a metodologia proposta neste estudo pode ser recomendada como prática para viveiros de produção de mudas que venham a propagar esta espécie. 


\section{CONCLUSÃO}

A escarificação mecânica com lixa em cilindro rotativo é uma técnica eficaz para a superação da dormência de sementes de pau-ferro.

O tempo de 15 segundos de escarificação para as sementes de pau-ferro é recomendado para a obtenção de germinação mais rápida e com maiores percentuais acumulados.

\section{REFERÊNCIAS}

AGRA, P.F.N.; GUEDES, R.S.; SILVA, M.L.M.; SOUZA, V.C.; ANDRADE, L.A.; ALVES, E.U. Métodos para a superação da dormência de sementes de Parkinsonia aculeata L. Semina: Ciências Agrárias, v. 36, n. 3, p. 1191-1202, 2015. Disponível em: http://www.uel.br/revistas/uel/index.php/semagrarias/article/view/12408. doi: 10.5433/1679-0359.2015v36n3p1191. Acesso em 17 de agosto de 2016.

ANDREANI JÚNIOR, R.; MELLO, W.S.; SANTOS, S.R.G.; KOZUSNY-ANDREANI, D.I. Superação da dormência de sementes de três essências florestais nativas. Três Corações, v. 12, n. 1, p. 470-479, 2014. Disponível em: http://revistas.unincor.br/index.php/revistaunincor/article/view/1390.

doi: 10.5892/ruvrd.v12i1.1390. Acesso em 09 de agosto de 2016.

AVELINO, J.I.; LIMA, J.S.S.; RIBEIRO, M.C.C.; CHAVES, A.P. RODRIGUES, G.S.O. Métodos de quebra de dormência em sementes de jucá (Caesalpinia ferrea Mart. ex Tul. var. ferrea). Revista Verde, v.7, n.1, p. 102 - 106, 2012. Disponível em: http://www.gvaa.com.br/revista/index.php/RVADS/article/view/853/pdf_374. Acesso em 17 de agosto de 2016.

BASKIN, C. C.; BASKIN, J. M. Seeds: Ecology, Biogeography, and Evolution of Dormancy and Germination. San Diego, CA, USA: Elsevier/Academic Press. Second edition. 2014.

BIRUEL, R.P.; AGUIAR, I.B.; PAULA, R.C. Germinação de sementes de pau-ferro submetidas a diferentes condições de armazenamento, escarificação química, temperatura e luz. Revista Brasileira de Sementes, v. 29, n. 3, p. 151-159, 2007. Disponível em: www.scielo.br/scielo.php?script=sci_arttext\&pid=S010131222007000300018. Acesso em 09 de agosto de 2016.

BRASIL. Ministério da Agricultura e Reforma Agrária. Instruções para análise de sementes de espécies florestais. Brasília: SNDA/CGAL, 2013. 97p.

CARVALHO, P. E. R. Espécies Arbóreas Brasileiras. Brasília: EMBRAPA Informação Tecnológica. Colombo, PR: EMBRAPA Florestas, v. 1, 2003. 1039 p.

COELHO, M. de F.B.; MAIA, S.S.S.; OLIVEIRA, A.K.; DIÓGENES, F.E.P.Superação da dormência tegumentar em sementes de Caesalpinia ferrea Mart ex Tul. Revista Brasileira de Ciências Agrárias, v. 5, n. 1, p. 74-79, 2010. Disponível em: http://www.agraria.pro.br/sistema/index.php?journal=agraria\&page=article\&op=view\& 
path $\% 5 \mathrm{~B} \% 5 \mathrm{D}=$ agraria_v5i1a570\&path\%5B\%5D=622. Acesso em 18 de agosto de 2016.

COELHO, M.de F.B.; NETO, M.H.C.; BARBOSA, M.K.R.; OLIVEIRA, M.C.; LIMA, A.K.B.L.B. Superação da dormência em sementes de Caesalpinia ferrea Mart. ex Tul. var. ferrea de duas populações. Revista Verde, v. 8, n. 4, p.179 - 182, 2013. Disponível em: <http://www.gvaa.com.br/revista/index.php/RVADS/article/view/2307/2049>. Acesso em 09 de agosto de 2016.

FERREIRA, A. G.; BORGHETTI, F. Germinação: do básico ao aplicado. Porto Alegre: Artmed, 2004. 323 p.

FERREIRA, C.; LOPES, I.; LÚCIO, A.R.N. Métodos para superar dormência em sementes de Enterolobium contortisiliquum (Vell.) Morong. Engenharia Ambiental, v. 10, n. 1, p. 043-047, 2013. Disponível em: www.unipinhal.edu.br/engenhariaambiental/include/getdoc.php.. Acesso em 09 de agosto de 2016.

FREIRE, J.M.; ATAIDE, D.H.S.; ROUWS, J.R.C. Superação de Dormência de Sementes de Albizia pedicellaris (DC.) L. Rico. Floresta e Ambiente, v. 23, N. 2, P. 251-257, 2016. Disponível em: http://www.scielo.br/pdf/floram/2016nahead/21798087-floram-2179-8087104514.pdf. doi:/10.1590/2179-8087.104514. Acesso em 09 de agosto de 2016.

FREITAS, A.R. de; LOPES, J.C.; MATHEUS, M.T.; MENGARDA, L.H.G.; VENANCIO, L.P.; CALDEIRA, M.V.W. Superação da dormência de sementes de jatobá. Pesquisa Florestal Brasileira, v. 33. n. 77, p. 85-90, 2013. Disponível em: http://pfb.cnpf.embrapa.br/pfb/index.php/pfb/article/view/350. Acesso em 09 de agosto de 2016.

GOMES, M.B.; FARIA, A.A.; CERQUEIRA, D.S.; BAILÃO, L.L. Avaliação de métodos para a superação de dormência de sementes de jatobá (Hymenaea courbaril I.). Revista Eletrônica da Univar, v. 2, p. 6, p. 6-9, 2013. Disponível em: http://revista.univar.edu.br/index.php/interdisciplinar/article/view/45. Acesso em 18 de agosto de 2016.

KIKUTI, A.N.; MARCOS FILHO, J. Testes de vigor em sementes de Alface. Horticultura Brasileira, v. 30, p. 44-50, 2012. Disponível em: http://www.scielo.br/pdf/hb/v30n1/v30n1a08.pdf. doi:10.1590/S010205362012000100008 . Acesso em 22 de agosto de 2016.

KRZYZANOWSKI, F.C.; VIEIRA, R.D.; FRANÇA NETO. J.B. Vigor de sementes: Conceitos e testes. Londrina: ABRATES, 1999. 218p.

LORENZI, H. Árvores Brasileiras: Manual de Identificação e Cultivo de Plantas Arbóreas Nativas do Brasil. Nova Odessa: São Paulo, 2000. 352p. 
MAGUIRE, J. D. Speed of germination-aid in selection and evaluation for seedling emergence and vigor. Crop Science, v. 2, n. 1, p. 176-177, 1962.

MARCOS FILHO, J. Fisiologia de sementes de plantas cultivadas. Piracicaba: FEALQ, 2005. 495p.

MEDEIROS, J.X. de; SILVA, G.H.S.; RAMOS, T.M.; LUCENA, D.S.; LUCIO, A.M.F.N. Efeito do substrato na germinação de sementes de embiratanha (Pseudobombax marginatum) e métodos de superação da dormência em sementes de jucá (Caesalpinia ferrea). Engenharia Ambiental, v. 10, n. 3, p. 113-121, 2013. Disponível em: http://ferramentas.unipinhal.edu.br/engenhariaambiental/viewarticle.php?id=903. Acesso em 18 de agosto de 2016.

NASCIMENTO, I.L. Determinação de metodologias para teste de germinação e vigor de sementes de quixabeira (Bumelia obtusifolia Roem et Schult. var. excelsa (DC) Mig.). Revista Árvore, v. 37, n. 4, p. 701-706, 2013. Disponível em: http://www.bibliotecaflorestal.ufv.br/handle/123456789/11050.

doi:10.1590/S0100-67622013000400013. Acesso em 18 de agosto de 2016.

OLIVEIRA, O.S. Tecnologia de sementes florestais. Curitiba: UFPR, 2012. 404p.

PICOLOTTO, D.R.N.; THEODORO, J.V.C.; DIAS, A.R.; THEODORO, G.F.; ALVES, C.Z. Germinação de sementes de urucum em função de métodos de superação de dormência e temperaturas. Pesquisa Agropecuária Tropical, v. 43, n. 3, p. 232238, 2013. Disponível em: www.agro.ufg.br/pat. doi:10.1590/S198340632013000300004 . Acesso em 16 de agosto de 2016.

RODRIGUES, R.R.; BRANCALION, P.H.S. Pacto pela restauração da Mata Atlântica. São Paulo: LERF, 2010. 259p.

SANTOS, L.W. Dos; COELHO, M.F.B.; MAIA, S.S.S.; SILVA, R.C.P.; CANDIDO, W.S.; SILVA, A.C. Armazenamento e métodos para a superação da dormência de sementes de mulungu. Semina: Ciências Agrárias, v. 34, n. 1, p. 171-178, 2013. Disponível em: http://www.uel.br/revistas/uel/index.php/semagrarias/article/view/8187. doi:10.5433/1679-0359.2013v34n1p171. Acesso em 16 de agosto de 2016. 